\title{
Ciência moderna e prática dos cientistas: um estudo a partir dos discursos e das rotinas dos pesquisadores do Centro de Ciências Agrárias da Universidade Federal de Viçosa ${ }^{1}$
}

\author{
Modern Science and practice of scientists: a study from the \\ discourses and routines of the researchers of the Centre of \\ Agricultural Sciences of the Federal University of Viçosa
}

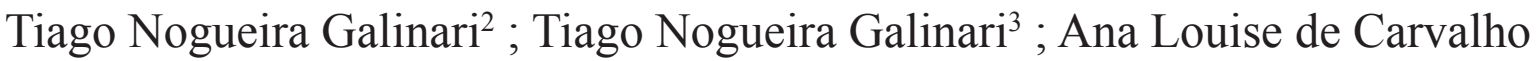
Fiúza $^{4}$; Yasmin Vieira Gonçalves ${ }^{5}$; Fernanda Henrique Cupertino Alcantara ${ }^{6}$
\end{abstract}

\section{Resumo}

Este estudo objetivou discutir o processo de assimilação da Ciência e seus produtos na vida social, a partir do advento da modernidade, e apresenta alguns dos discursos a respeito da sua função emancipadora e as posteriores reações críticas a estes discursos. Utiliza-se, como ilustração, uma análise aos discursos e às rotinas de pesquisadores dos programas de pós-graduação stricto sensu do Centro de Ciências Agrárias da Universidade Federal de Viçosa (CCA/UFV). Para tal, como procedimento metodológico, além de profundo levantamento bibliográfico, foi entrevistada uma amostra representativa de 68 pesquisadores do $\mathrm{CCA} / \mathrm{UFV}$. Com base nas averiguações feitas, verificou-se que os conhecimentos científicos produzidos pelos pesquisadores do CCA/UFV estão em consonância com as lógicas da Ciência moderna, pois, além de haver uma grande especialização dos cientistas, o setor produtivo exerce importante influência em suas práticas e rotinas.

Palavras chave: Ciência moderna. Cientistas. Ciências agrárias. Universidade Federal de Viçosa.

\begin{abstract}
This study aimed to discuss the process of incorporating Science and its products in the social sphere from the advent of modernity, presenting some of the discourses on their emancipatory function and subsequent critical reactions to these discourses. An analysis of the discourses and routines of researchers of strictu sensu post-graduate programs of the Center for Agricultural Sciences of the Federal University of Viçosa (CCA / UFV) was used as an example. The methodological procedure was conducted as interviews for a representative sample of 68 researchers from the CCA/UFV. Based on
\end{abstract}

\footnotetext{
1 Parte da dissertação de mestrado do primeiro autor, intitulada "Interesses públicos e privados nos discursos e nas rotinas dos professores do Centro de Ciências Agrárias da Universidade Federal de Viçosa-MG”, defendida em 2010, no programa de Mestrado em Extensão Rural do Departamento de Economia Rural da Universidade Federal de Viçosa.

${ }^{2}$ Geógrafo. Mestre em Extensão Rural. Professor da Universidade Estadual de Mato Grosso do Sul. tiagogalinari@yahoo.com.br.

${ }^{3}$ Geógrafo. Mestre em Extensão Rural. Professor da Universidade Estadual de Mato Grosso do Sul. tiagogalinari@yahoo.com.br

4 Socióloga. Doutora em Desenvolvimento Rural. Professora Adjunta do Departamento de Economia Rural da Universidade Federal de Viçosa. louisefiuza@ufv.br.

5 Geógrafa. yasmin.goncalves@ufv.br

${ }^{6}$ Socióloga. Doutora em Sociologia. Professora Adjunta do Departamento de Economia Rural da Universidade Federal de Viçosa. falcantara@ufv.br
} 
the inquiries made, it was found that the knowledge produced by researchers at CCA/UFV is consistent with the logic of modern Science. Besides having highly specialized scientists, the productive sector has an important influence on the practices and routines of the researchers.

Keywords: Modern Science. Scientists. Agricultural sciences. Federal University of Viçosa.

\section{Introdução}

A Ciência e a tecnologia, na atualidade, estão presentes nas várias instâncias que regem a vida em sociedade - nas convenções políticas e econômicas, bem como na produção de bens e no mercado de consumo - tornando-se relevante entender como se dá a produção e disposição do conhecimento científico em nossa sociedade.

Desse modo, este artigo traz uma análise do processo de incorporação da Ciência e seus produtos - as tecnologias - pela sociedade a partir do advento da modernidade, ponderando acerca do modo como se construíram os discursos sobre a sua função emancipadora e as reações críticas posteriores a estes discursos. Para uma contextualização empírica da análise à prática científica supracitada, são considerados, também, os discursos e rotinas dos pesquisadores do Centro de Ciências Agrárias da Universidade Federal de Viçosa (CCA/UFV).

\section{A Construção da Ciência}

Existem diversas compreensões e discussões acerca do significado da Ciência e do seu verdadeiro papel perante a sociedade. O discurso que considera o conhecimento científico um instrumento para a emancipação humana e para o progresso da sociedade disputa espaço com a premissa de que a Ciência e suas tecnologias são, na verdade, artifícios para manutenção da alienação dos indivíduos. Se a influência da Ciência sobre a vida dos indivíduos apresenta controvérsias quanto ao julgamento, da mesma forma a conceituação acerca da Ciência apresenta diversas definições e interpretações.

A Ciência comumente é entendida como sendo um campo de investigação e de descobertas, em que os cientistas utilizam rigorosos métodos para produzirem conhecimento, por meio de procedimentos que possam ser reproduzíveis por outros cientistas. Outras vezes, a Ciência é vista meramente como a busca pela verdade, como destacaram Fontes e Cardoso (2006). Em contrapartida a esta associação da Ciência com a verdade, Bondi (1976) ponderou que a Ciência é mais bem definida como sendo a compreensão do mundo a partir de determinada teoria $^{7}$ científica, admitindo-se a influência de fatores socioeconômicos relativos a um determinado momento histórico sobre a mesma. De acordo com este autor, uma teoria pode representar, em um determinado momento histórico, uma verdade incondicional, socialmente e culturalmente aceita e, em outro momento, esta mesma teoria pode ser refutada, tornando-se inválida, abrindo caminho para que outra teoria assuma essa posição de veridicidade.

Confluente com esta perspectiva, Kuhn (1987) caracterizou como Ciência normal aquela delineada e baseada em um paradigma aceito durante algum tempo por uma comunidade de cientistas. Para o autor, os paradigmas são os modelos (leis, teorias, práticas e aplicações) aceitos e que se tornaram tradições seguidas por determinado campo de pesquisa ${ }^{8}$. Mas, segundo Kuhn (1987), a Ciência sai de seu estado de normalidade quando um paradigma aceito pela comunidade científica é total ou parcialmente

\footnotetext{
7 Uma teoria científica pode ser entendida como um enunciado geral, passível de refutação através de um determinado método científico empírico, em que é afirmado que as coisas ou fenômenos de determinada espécie se arranjam ou se comportam de certa forma (BONDI, 1976).

8 Um campo de pesquisa é um sistema que abrange métodos, técnicas, tecnologias, formas de observação e de experimentação e conceitos embasados por determinadas teorias que permitem conhecer e analisar diversas coisas e fenômenos (KUHN, 1987)
} 
substituído por outro. Isto caracteriza uma revolução científica. De acordo com este autor, o progresso da Ciência não é causado pelo acúmulo de descobertas ao longo da história, mas, sim, devido às Revoluções Cientificas.

Já, de acordo com Bondi (1976), o progresso da ciência ocorre quando surge a possibilidade contínua de se realizar mais experimentos e de se desenvolver novas metodologias científicas para a refutação ou reafirmação de determinada teoria por meio de estudos específicos. A tecnologia, nesse sentido, tem papel fundamental para este progresso. Ela é produzida a partir da ciência e gerando, por sua vez, novos meios para o experimentador e para o observador analisar dada realidade. Desse modo, o progresso da ciência provoca um progresso tecnológico, que, também, possibilita o avanço dos testes e das técnicas referentes às teorias científicas e potencializando o progresso das Ciências (BONDI, 1976).

\section{A revolução científica enquanto processo de constituição da Ciência}

O termo Revolução cientifica é empregado de maneira diferente pelos historiadores da Ciência quando comparado com a acepção que Kuhn (1987) emprega. Como destacou Henry (1998), os historiadores da Ciência denominam de Revolução cientifica o período que teve início nos séculos XVI e XVII, com consolidação no século XVIII, em que ocorreu grande reformulação dos fundamentos conceituais, metodológicos e institucionais da Ciência moderna européia, tornando-a cada vez mais especializada e formalizada. Porém, segundo o mesmo autor, antes deste período, o termo mais correto para designar a produção do conhecimento, ao invés de de Ciência, era o de filosofia natural. Isto porque, antes de tal revolução, os estudiosos almejavam descrever e explicar o sistema mundo em sua totalidade, influenciados em suas teses por uma grande multiplicidade de domínios do conhecimento.

Osfilósofos naturais faziamusode fundamentações em disciplinas derivadas da matemática (astronomia, geometria, ótica, cinemática) e da medicina (anatomia, fisiologia, farmacologia), principalmente, além de diversas artes plásticas, como a navegação, cartografia, mineração e cirurgia, entre outras. Do ponto de vista metodológico, como explicou Henry (1998), a "matematização da natureza" e o "método experimental" foram importantes elementos para a realização desta Revolução científica. A matemática deixou de ser predominantemente instrumentalista - com teorias propostas apenas de modo hipotético e visando a pouca aplicação -, se tornando, continuamente, mais realista - visando mais aplicação da matemática para explicar os diferentes fenômenos e fazendo dos cálculos predições da realidade e de como as coisas deveriam ser.

Devido, entre outras coisas, à incorporação "aplicada" da matemática aos interesses dos governos, com a incorporação de técnicas derivadas desta área do conhecimento (como a topografia e a engenharia bélica, por exemplo), a matemática passou a desempenhar maior realce e importância social, cultural e política. Aliado à "matematização", novos instrumentos, aparelhos, técnicas e métodos matemáticos foram incorporados aos procedimentos científicos, fazendo com que fossem desenvolvidos experimentos específicos para cada propósito analítico. A promoção do método experimental foi facilitada, então, pela tendência ascendente de quantificação dos resultados das pesquisas, oriunda do advento do modelo matemático científico.

Segundo Henry (1998), outra importante ruptura da ciência com a filosofia natural é no que se refere ao surgimento da filosofia mecânica. O autor

\footnotetext{
${ }_{9}$ Um dos mais importantes sistemas de pensamento filosófico-teológico vinculados ao catolicismo, responsável pela forma como foi pensada e produzida grande parte da ciência desenvolvida na Idade Média, baseando-se em doutrinas do filósofo grego Aristóteles (384 a.C - 322 a.C) e de seu aparato conceitual e metodológico (HENRY, 1998).
} 
demonstrou como que este novo modo de pensar e explicar as coisas, gradativamente, substituiu o aristotelismo escolástico $^{9}$ que imperava na perspectiva da filosofia natural. No entendimento dos filósofos mecânicos, quase todos os fenômenos, incluindo as formas, processos e funções vitais, eram passíveis de explicação por conceitos - entre eles o de forma, tamanho, quantidade e movimento - provenientes da disciplina matemática mecânica. Até mesmo qualidades ocultas eram possíveis de sofrer elucidações perante esses conceitos, já que a filosofia mecânica se fundava na premissa de que os corpos eram constituídos por minúsculas partículas invisíveis - posteriormente, denominados de átomos. Isso ficou explícito em "Discurso do Método", de René Descartes (1596-1650), em que o autor procurou demonstrar de forma pioneira, embora sucinta, toda a mecânica do funcionamento do coração humano (DESCARTES, 2005).

A Ciência, então, a partir do século XVII e, sobretudo a partir da segunda metade do século XIX, como apontou Meis (1994), tornou-se cada vez mais institucionalizada, organizada e formalizada em universidades, empresas e outras entidades, gerando, a partir disso, uma produção exponencial de novos conhecimentos, determinando grandes mudanças sociais em nosso planeta. Fica claro o quanto o formato político-econômico, sociocultural e profissional das pesquisas científicas e da produção do conhecimento pela ciência contemporânea rompeu drasticamente com o modelo característico do praticado pela filosofia natural. Nos últimos séculos, continuamente, a Ciência ganhou grande realce e importância social, política e econômica, e isso fez com que, sucessivamente, novos campos de pesquisa surgissem, tornando-se cada vez mais especializados em determinadas investigações ou na resolução de especificidades.

\section{A institucionalização da produção científica}

Esta racionalidade idealizada pela ciência e a conseguinte institucionalização da produção científica se devem, principalmente, entre outros colaboradores, à Francis Bacon (1561-1626) e à René Descartes. Embora apresentem pensamentos diferenciados-Bacon, pensando a produção científica externamente, num viés organizacional, possível de ser institucionalizada; enquanto Descartes, enxerga essa produção internamente, na Ciência feita pelo indivíduo, acreditando na possibilidade de qualquer sujeito poder fazer ciência, bastando ter rigor metodológico e tendo razão em suas experimentações, mesmo quando feitas isoladamente - estes dois autores da renascença acreditavam que a Ciência possibilitaria a emancipação dos sujeitos, atuando como força libertadora, tanto para o indivíduo como para a sociedade (BACON, 1984; DESCARTES, 2005).

Embora o moderno modelo institucionalizado pela Ciência apresente elementos tanto cartesianos sobretudo no que diz respeito ao rigor metodológico e à matematização - como baconianos, tornandose difícil determinar a seleção de um modelo em detrimento do outro, nota-se que, de maneira geral, as premissas baconianas foram mais notadamente incorporadas. Pois, além da crença na Ciência como possibilitadora e potencializadora do avanço técnico, social e econômico, na moderna Ciência institucionalizada, as organizações formais e as redes de pesquisa - e seus equipamentos, materiais e técnicas - são enfatizados como sendo os fatores mais importantes para o progresso.

O conhecimento científico, a partir da Revolução cientifica, na maior parte das vezes, passou a ser entendido como a condição a priori da emancipação humana, trazendo no seu bojo a tecnologia como seu produto e instrumento. Rouanet (1989), discorrendo

\footnotetext{
${ }^{10}$ Movimento intelectual e artístico, surgido no século XVIII na Europa, que reorientou a produção do conhecimento, baseando-se, principalmente, na premissa de que o "atrasado" da Idade Média deveu-se à falta de esclarecimento, sendo, deste modo, a ciência uma das principais possibilitadoras do progresso para a sociedade (ROUANET, 1989).
} 
acerca da ciência, a partir da Ilustração ${ }^{10}$, demonstrou como ela passou a ser vista como libertadora da magia e da falta de esclarecimento, mesmo que não se desconsiderasse que a sua institucionalização na sociedade capitalista a tenha institucionalizado, sem construir uma reflexão a respeito de seus efeitos sobre o mundo. Assim, na contemporaneidade, a Ciência interpretada como a priori da emancipação social e promotora da libertação dos sujeitos, passou a ser alvo de inúmeras críticas. Estas críticas, logicamente, não partem da tese de que o conhecimento científico não pode ter caráter emancipador, mas sim, que para isto ocorrer, a ciência deveria ser, antes de qualquer coisa, problematizada, criticada e socializada.

Em crítica a esta falta de reflexividade da Ciência, Habermas (2007) esclareceu que o progresso técnicocientífico passou a despontar como uma variável quase independente, passando a depender dela, inclusive, o crescimento econômico. Albuquerque (2009) demonstrou como que, para obterem sucessos, as estratégias políticas que visam o crescimento econômico e industrial passaram a necessitar de investimentos numa base técnico-científica, tornando os países cada vez mais dependentes de capacitados e planejados sistemas de inovação tecnológica.

Nesse sentido, Habermas (2007) afirmou que a cientificização da técnica tornou-se o alicerce da força produtiva industrial ${ }^{11}$. Schwartzman (2002) acrescentou a essa compreensão de Habermas que, além da Ciência penetrar no mundo da indústria, também ocorreu uma penetração do modelo industrial na produção de conhecimento. Além das metodologias e dos procedimentos técnicos de pesquisa, ocorreu, também, uma transformação na cultura e nas instituições dentro das quais as atividades científicas se desenvolvem.

Continuando a sua crítica ao formato da produção científica moderna, Habermas (2007) concluiu estar ausente nas Ciências a reflexão acerca dos interesses que conduzem à produção do conhecimento. Assim, a partir de resultados objetivos e tentando se proteger das coações e seduções privadas, a Ciência pensa estar livre dos arranjos produzidos pelos interesses particulares, porém, os interesses particulares não deixam de fundamentar e condicionar a realização de uma investigação científica. Nesse sentido, o autor afirma que é necessário que a Ciência crie mecanismos que possibilitem o enfrentamento dos riscos presentes nas conexões entre a produção dos conhecimentos e seus possíveis interesses.

\section{Ciências e Cientistas}

O desenrolar da Ciência e sua conseguinte institucionalização na modernidade influenciaram , sucessivamente, o surgimento e desenvolvimento de novos campos de pesquisa e de investigação, cada vez mais especializados. Os filósofos naturais, como foi salientado por Henry (1998), almejavam investigar o mundo de maneira genérica, porém o amadurecimento da Ciência fez com que os cientistas passassem a delimitar campos de estudo cada vez mais particulares, passando também a descrever e explicar realidades cada vez mais diferenciadas entre si. O pensamento cartesiano influenciou muito para a efetivação dessa fragmentação da construção do conhecimento. De acordo com este modelo de pensamento, a melhor compreensão das coisas e dos fenômenos ocorre quando há maior objetividade na investigação e, para isso, as Ciências deveriam ser divididas em disciplinas (DESCARTES, 2005).

No que diz respeito, ainda, à fragmentação da Ciência na modernidade, é importante salientar que ela também se deu a partir de uma concepção que diferenciava a objetivação da produção do conhecimento como sendo "puro" ou "aplicado".

\footnotetext{
${ }^{11}$ Um bom exemplo dessa transferência de fundamentos da ciência visando o incremento da produtividade industrial está relacionado com Taylor (1856-1915), considerado "pai” da administração científica. Na concepção taylorista, a eficiência operacional é buscada a partir da racionalização do trabalho, contabilizando o tempo de execução das diferentes tarefas, do planejamento e controle do processo produtivo e da preparação dos trabalhadores para executarem tarefas específicas (MORAES NETO, 1991).
} 
Com base nessa concepção, a pesquisa básica seria constituída "com o intuito de conhecer a natureza" e a pesquisa aplicada "com a intenção de controlar a natureza e modificar ou prever o evento" (ALVES; SZMRECSANYI; MARCOS, 1982, p. 56-57). De acordo com essa concepção, fica a encargo da Ciência pura descobrir novos elementos da natureza e investigá-los. Das pesquisas aplicadas decorre a manipulação e utilização prática dos conhecimentos adquiridos acerca da natureza.

A forma disciplinar de investigar e a delimitação do objeto de estudo em áreas distintas do conhecimento fez a Ciência ganhar diferentes subdivisões conceituais. Essa fragmentação gerou a constituição de distintos ramos do conhecimento, que deu origem, por sua vez, aos domínios do conhecimento: Ciências sociais, exatas, biológicas e da natureza, dentre tantas outras especificações feitas (WEIL; D’AMBROSIO; CREMA, 1993).

De acordo com Henry (1998), na medida em que a produção do conhecimento ganhou destaque junto aos diferentes Estados, produzindo conhecimentos aplicados aos interesses governamentais (como a topografia e a engenharia bélica, por exemplo), os estudiosos também passaram a auferir de mais prestígio e visibilidade. Inúmeros foram os casos de proeminentes matemáticos e astrônomos que, no momento de passagem da Revolução Científica, nos séculos XVI e XVII, receberam importantes cargos e títulos, como de conselheiros reais ou de filósofos da corte, por exemplo (HENRY, 1998).

Depois de já estabelecida a Ciência moderna, as possibilidades de promoção enquanto cientistas intensificaram-se, tornando-se cada vez mais possíveis as chances de ascensão dos pesquisadores na carreira científica. Como destacaram Latour e Woolgar (1997), é comum os cientistas mudarem, inclusive, o seu campo de atuação, a fim de ocupar a posição que acreditam que lhes possibilitaria maiores chances de ascensão econômica, profissional e de ganho de status dentro da carreira científica.
De acordo com Latour e Woolgar (1997), a carreira do cientista é compreendida dentro de uma perspectiva de sua trajetória individual, em que se salienta a quantidade e qualidade de posições sucessivamente ocupadas por ele ao longo de sua atuação profissional como pesquisador. Para os autores, o curriculum vitae apresenta o saldo de todos os investimentos aplicados à sua carreira.

O sinal de um investimento bem-sucedido para um pesquisador pode ser, por exemplo, o número de telefones recebidos, a aceitação de seus artigos, os interesses que os outros demonstram pelo seu trabalho, o fato de que seja mais facilmente bem acreditado ou ouvido com maior atenção, que lhe proponham melhores ocupações, que seus testes dêem resultado, que seus dados se acumulem de maneira mais confiável e formem um conjunto mais digno de crédito (LATOUR; WOOLGAR, 1997, p. 233).

De acordo com os autores, a busca pelo crédito e pela credibilidade são os principais motivadores das práticas científicas realizadas pelos pesquisadores. O crédito obtido pelo trabalho científico leva ao reconhecimento - por sua vez, facilitando o alcance de prestígio e ganho de recursos para continuidade das pesquisas. Já a credibilidade leva à confiabilidade nos trabalhos dos pesquisadores e o conseguinte respeito entre os seus pares. Desta forma, fica explícito como a institucionalização das práticas científicas, assim como os ganhos de prestígio e notoriedade da Ciência demonstram os campos de forças e de disputas existentes na produção do conhecimento científico.

\section{A técnica e a tecnologia como produtos sociais}

Assim como ocorre com a Ciência, existe grande diversidade quanto ao entendimento acerca do significado e da importância das técnicas e das tecnologias para a sociedade. Porém, apesar da divergência quanto ao papel da técnica e da tecnologia para o ser humano, é fato reconhecido que a produção e a difusão das mesmas nos espaços e nas sociedades são percebidas como influenciadas por fatores políticos, culturais, socioeconômicos, 
bem como também influenciam para a dinâmica das relações sociopolíticas e econômicas da sociedade.

A técnica, de acordo com Neves (2006a), se constitui em uma atividade realizada por qualquer organismo vivo - ato técnico - que cria e usa algo distinto de si próprio - um artefato técnico. Assim, qualquer animal pode realizar um ato técnico produzindo um artefato exterior a si mesmo. Entretanto, o mesmo autor apontou diferenças substanciais das técnicas humanas em relação às demais, principalmente, no que se refere à produção dos artefatos técnicos, que são infinitamente mais aprimorados na produção humana. Brüseke (2001) também defende a perspectiva de que as técnicas fazem parte da essência do homem e destaca que a técnica humana liberta o homem da necessidade de adaptação orgânica, característica da técnica produzida pelos animais, e os capacitam para a transformação das circunstâncias às suas necessidades e desejos. A técnica seria, para o homem, uma espécie de natureza artificial e essencial. A transformação da natureza pelo homem, que ocorre desde os tempos mais remotos da história humana, seria uma expressão do uso das técnicas pelo "homem".

A técnica seria uma tentativa do "homem" de estabilizar o ritmo do mundo, através do domínio das irregularidades e exceções. Tal tentativa de domínio da natureza estaria presente tanto nas técnicas modernas, como nas formas de magia, apontando para o fato de que em todos os tempos e culturas humanas buscou-se a utilização de meios para se garantir a repetição homogênea de certos fenômenos naturais, como a chuva, a chegada da estação certa para o plantio e a colheita, a proteção contra secas e enchentes, etc. (BRÜSEKE, 2001). Com o passar do tempo, como observado por Neves (2006b), tornouse notável como a técnica passou a estar cada vez mais conectada ao ser humano.

Essa aceleração da ligação do humano à sua natureza artificial fez com que alguns passassem a pensar o ser humano moderno como um híbrido. Para Neves (2006b), o ponto crítico dessa alta conectividade do homem à técnica é a possibilidade da criatividade e inventividade humana cederem espaço à simples "adaptatividade". Isso se evidencia na tecnociência, na qual há uma tendência majoritária de direcionamento da Ciência para as questões prático-instrumentais, tendo como principal finalidade o desenvolvimento de conhecimentos para solucionar os distintos problemas de ordem técnica (PERMEBIDA, 2004).

Comumente, a trajetória da tecnologia - tomada como produto de pesquisas aplicadas - é interpretada a partir de uma concepção restrita dos impactos produzidos por ela no meio social, econômico e político. Este modelo de interpretação, como explicou Benakouche (1999), é limitado, pois não revela os impasses e os desvios que ocorrem na trajetória seguida pela tecnologia e o papel exercido pelos diferentes sujeitos em tal trajeto. Assim, a autora propõe como alternativa a esta interpretação um modelo multidirecional, em que estes mesmos agentes se inter-relacionam em um "emaranhado", não exclusivamente retilíneo, de conexões. Neste modelo, procura-se reconhecer as tramas de relações - culturais, econômicas, políticas e sociais - envolvidas na produção, difusão e uso das tecnologias, a partir de uma rica rede de atores - indivíduos, leis, projetos, empresas, Estados, entre outros (BENAKOUCHE, 1999).

Sendo um produto da visão social de mundo que impera em uma sociedade e em um período histórico específico, a Ciência desde a segunda metade do Século XX, após o impacto trazido pelos danos provocados pelas bombas atômicas, pelas chuvas ácidas e desastres ambientais, vem, crescentemente, incorporando o sentido de risco. Assim, a Ciência passou a incorporar na contemporaneidade a preocupação com a sustentabilidade do planeta e seus habitantes.

A experiência negativa da técnica moderna, em virtude da sua utilização ambientalmente indevida, e os possíveis riscos oferecidos pelas tecnologias à sociedade gerou desconfiança e busca por precaução 
(BRÜSEKE, 2001). Devido a esse fato surgiram, durante as décadas de 1960 e 1970, surgiram várias críticas à tecnologia moderna. A partir de então, novas concepções e idéias acerca do papel da tecnologia em face da sociedade passaram a ser discutidas (ANDRADE, 2006). Dentro desta perspectiva de se considerar os possíveis riscos socioambientais da utilização de determinadas tecnologias, as mesmas começaram a ser reinventadas de modo mais sustentável e, inclusive, como possíveis ferramentas para reverter danos já causados e evitar outros futuros, como por exemplo, as tecnologias limpas ${ }^{12}$ e alternativas. Porém, grande parte das vezes, como destacou Andrade (2006), estas tecnologias possuíam um caráter substitutivo, não conseguindo superar por completo o modelo clássico das tecnologias convencionais.

A partir da idéia e da crítica à Ciência e tecnologia como promotoras a priori da libertação e emancipação humana emergiu o pensamento de valorização dos conhecimentos locais, em detrimento da massificação da técnica provocada pela supervalorização das tecnologias convencionais. Seguindo essa perspectiva, Dagnino, Brandão e Novaes (2004) apontaram a construção e o desenvolvimento de tecnologias sociais como uma alternativa às tecnologias convencionais, em que, as primeiras, diferentemente das segundas, são produzidas localmente para e com os atores que farão uso das mesmas, podendo ser mais sustentáveis ambientalmente e socialmente, além de serem adaptáveis aos pequenos empreendimentos. As tecnologias sociais, para os autores, têm como principal objetivo a emancipação dos sujeitos. Neste mesmo sentido, Teixeira e Lages (1996) demonstraram como, na tentativa de superar as crises provocadas pelo mau uso da tecnologia, fezse necessário o desenvolvimento de tecnologias que, além de serem socialmente menos excludentes, fossem também mais sustentáveis do ponto de vista ambiental, ou seja, tecnologias que não causassem nenhum risco socioambiental.

Após a realização de uma rápida historicização do surgimento e da trajetória da Ciência e da apresentação de perspectivas teóricas que discutem a dinâmica e papel da Ciência e da tecnologia para a sociedade, passaremos a análise da produção tecnológica em uma situação concreta, utilizandonos do processo de institucionalização das Ciências Agrárias na Universidade Federal de Viçosa - MG. Essa escolha se deveu ao fato de tal Universidade - e seu respectivo Centro de Ciências Agrárias - se constituido em uma das instituições que primeiro consolidaram a produção de conhecimentos científicos e tecnológicos no país, sobretudo no que diz respeito aos estudos agrícolas.

\section{Procedimentos Metodológicos}

A fim de verificar algumas características da prática científica dos pesquisadores do CCA/UFV e de seus discursos a respeito de suas práticas, além de analisar o enquadramento da produção científica nas lógicas da Ciência moderna, este trabalho delineouse como descritivo-explicativo, com coleta de dados primários, fazendo uso de variáveis - e abordagens - quantitativas e qualitativas.

\section{População e amostra}

Os professores pesquisadores dos programas de pós-graduação stricto sensu do CCA/UFV, campus Viçosa-MG, constituem a população deste estudo. Em 2009, esses programas somavam 235 orientadores de diversos departamentos desta Universidade, entretanto, o número de professores destes programas era menor que este valor, já que muitos professores atuavam como orientadores em mais de um programa. Cada um dos 10 programas possuía, neste mesmo ano, quantidades distintas de orientadores. $\mathrm{O}$ programa de Ciência Florestal era composto por 32

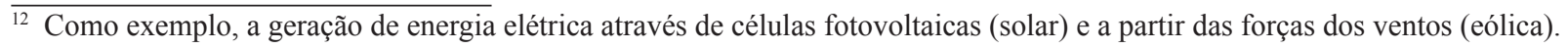


orientadores; o de Economia Aplicada era composto por 12 orientadores; o de Engenharia Agrícola era composto por 26 orientadores; o de Extensão Rural era composto por 11 orientadores; o de Fitopatologia era composto por 17 orientadores; o de Fitotecnia era composto por 39 orientadores; o de Genética e Melhoramento era composto por 37 orientadores; o de Meteorologia Agrícola era composto por 8 orientadores; o de Solos e Nutrição de Plantas era composto por 23 orientadores; e o de Zootecnia era composto por 30 orientadores.

Para este estudo, seguindo um nível de significância de $90 \%{ }^{13}$, a amostra representativa se constituiu de 68 orientadores. Foi sorteada uma amostra de 60 professores, entretanto, oito deles atuavam em dois programas distintos, sendo, por este motivo, contabilizados nos dois programas que orientavam. A disposição desta amostra foi probabilística. A partir do sorteio da população total (235 orientadores), passaram a fazer parte da amostra deste trabalho: 8 orientadores da Ciência Florestal, 5 da Economia Aplicada, 5 da Engenharia Agrícola, 4 da Extensão Rural, 6 da Fitopatologia, 11 da Fitotecnia, 12 da Genética e Melhoramento, 3 da Meteorologia Agrícola, 6 do Solos e Nutrição de Plantas e 8 da Zootecnia.

\section{Métodos e técnicas de coleta de dados}

Após os sorteios dos professores, os mesmos foram contatados e iniciaram-se as entrevistas, realizadas em escala de tempo transversal, entre os meses de agosto e novembro de 2009 . O roteiro das entrevistas foi organizado de forma estruturada e, a partir das mesmas, foi feito um levantamento acerca dos temas de pesquisa envolvidos nos estudos dos professores, sobre os fatores que mais os influenciam para a realização de suas pesquisas e a respeito do entendimento deles sobre as maiores contribuições de suas pesquisas para a sociedade.

\section{Organização e análise dos dados}

Com base nas respostas dadas pelos professores nas entrevistas, foram feitas categorizações das informações recebidas, agrupando estes dados em diferentes quadros temáticos. A partir destas informações e do escopo teórico desdobrado neste trabalho, foram realizadas as análises vistas a seguir.

\section{Cientistas do CCA/UFV: Discursos, Práticas e Produtos}

A Ciência e a tecnologia produzida pelos professores orientadores do Centro de Ciências Agrárias da Universidade Federal de Viçosa, assim como por quaisquer outros cientistas das mais distintas instituições, apresentam certas singularidades, como, também, características comuns aos cientistas modernos. $\mathrm{Na}$ pesquisa realizada junto aos pesquisadores do CCA/UFV ficou claro a importância que os mesmos atribuíam às suas pesquisas, devido ao fato das mesmas apresentarem a possibilidade de suprirem com as necessidades do setor produtivo e, consequentemente, com as da sociedade e do mercado consumidor.

Neste sentido, Benakouche (1999) ressalta que para analisar a inserção da tecnologia na sociedade sem cair numa visão tecnológica determinística $e$ fatalista $^{14}$ é preciso interpretá-la junto ao seu contexto político, social e econômico. A perspectiva crítica que trata a instrumentalização e organização da Ciência e da tecnologia vai além de um viés determinista - que percebe a evolução técnica apenas como condicionando o desenvolvimento econômico -, pois também pondera acerca da mesma influenciando e sendo influenciada pela sociedade em suas diferentes variáveis. As trajetórias das tecnologias podem ser relacionadas com a interveniência de determinados grupos sociais, com maior poder de influência no

\footnotetext{
13 A determinação da amostra foi feita baseada em Triola (2005).

14 Nesta perspectiva, as tecnologias são vistas isoladamente e interpretadas como produtoras dos arranjos sociais, se esquecendo, muitas vezes, que elas também são produtos sociais (BENAKOUCHE, 1999).
} 
processo de planejamento, produção e distribuição dos artefatos tecnológicos. Estes grupos, como apontado pela autora, são constituídos não apenas por especialistas, mas, também, por diferentes extratos da sociedade - políticos, empresários, entre outros. A seguir, apresentamos os dados referentes à forma como os pesquisadores do CCA/UFV percebem o direcionamento que é dado às pesquisas que realizam.

Observando o quadro 1, observa-se a diversidade de temas de pesquisa desenvolvidos pelos professores-pesquisadores do CCA/UFV.

Quadro 1 - Agrupamento dos principais temas / objetos analíticos de pesquisa dos programas de pósgraduação do $\mathrm{CCA} / \mathrm{UFV}^{15}$

\begin{tabular}{|c|c|}
\hline Programas de pós-graduação & Principais temas de pesquisa / objetos analíticos identificados \\
\hline Ciência Florestal & $\begin{array}{l}\text { Identificação, caracterização e avaliação de práticas sustentáveis } \\
\text { para indústria madeireira e de celulose e papel; caracterização } \\
\text { e melhoria da madeira para a indústria; desenvolvimento de } \\
\text { novas metodologias (e de espécies) para aumento / melhoria da } \\
\text { silvicultura (sustentável); mapeamentos visando a identificação } \\
\text { de áreas preservadas e degradas. }\end{array}$ \\
\hline Economia Aplicada & $\begin{array}{l}\text { Identificação, caracterização, avaliação e estimativa do mercado } \\
\text { na cadeia do agronegócio (nacional e internacional); identificação, } \\
\text { caracterização, avaliação e estimativas dos efeitos das políticas } \\
\text { para o agronegócio brasileiro; análise acerca do cooperativismo e } \\
\text { seus efeitos para o desenvolvimento. }\end{array}$ \\
\hline Engenharia Agrícola & $\begin{array}{l}\text { Avaliação e desenvolvimento de fontes energias alternativas } \\
\text { a serem utilizadas na agropecuária e nas máquinas agrícolas; } \\
\text { avaliação e desenvolvimento de métodos para silagem; avaliação } \\
\text { e desenvolvimento de maquinários para agropecuária; avaliação e } \\
\text { desenvolvimento de modelos de manejo para irrigação. }\end{array}$ \\
\hline Extensão Rural & $\begin{array}{l}\text { Caracterização e desenvolvimento de percepções alternativas } \\
\text { sobre temas envolvendo as novas ruralidades (questões de gênero, } \\
\text { pluriatividade, etc.); análise da produção (e difusão) da ciência e } \\
\text { tecnologia para o campo; análise acerca do cooperativismo e seus } \\
\text { efeitos para o desenvolvimento. }\end{array}$ \\
\hline Fitopatologia & $\begin{array}{l}\text { Identificação, caracterização, avaliação e desenvolvimento de } \\
\text { métodos de controle biológico; identificação, caracterização } \\
\text { e avaliação de doenças, e o desenvolvimento de métodos para } \\
\text { tratamento. }\end{array}$ \\
\hline Fitotecnia & $\begin{array}{l}\text { Avaliação e desenvolvimento de melhoramento genético de } \\
\text { plantas; identificação, caracterização, avaliação e desenvolvimento } \\
\text { de métodos de manejo integrado para plantas daninhas. }\end{array}$ \\
\hline
\end{tabular}

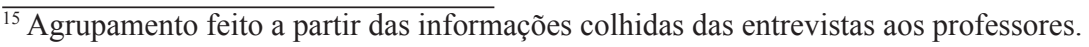


continuação...

\begin{tabular}{|c|l|}
\hline Genética e melhoramento & $\begin{array}{l}\text { Avaliação e desenvolvimento de melhoramento genético de } \\
\text { plantas; identificação e caracterização genética de plantas e } \\
\text { insetos. }\end{array}$ \\
\hline \multirow{3}{*}{ Metereologia Agrícola } & $\begin{array}{l}\text { Caracterização, avaliação e estimativa da interação atmosfera- } \\
\text { solo-planta; avaliação e desenvolvimento de modelos } \\
\text { climatológicos (climatologia estatística). }\end{array}$ \\
\hline \multirow{3}{*}{ Solos e Nutrição de Plantas } & $\begin{array}{l}\text { Avaliação e desenvolvimento de métodos para a nutrição de } \\
\text { plantas; caracterização, avaliação e desenvolvimento de métodos } \\
\text { de manejo integrado (e sustentável) dos solos; identificação, } \\
\text { caracterização e avaliação dos solos. }\end{array}$ \\
\hline Zootecnia & $\begin{array}{l}\text { Avaliação e desenvolvimento de melhoramento genético } \\
\text { de animais; identificação, caracterização, avaliação e } \\
\text { desenvolvimento de métodos para a produção e conservação de } \\
\text { forragem e ração; avaliação e desenvolvimento de métodos para } \\
\text { a nutrição e bem-estar animal. }\end{array}$ \\
\hline
\end{tabular}

Fonte: Dados de pesquisa, 2009

Como visto, os programas de pós-graduação do CCA/UFV se propõem a investigar uma gama de temas, e isso acarreta uma significativa disciplinaridade: "fragmentam-se" as áreas de estudo e elas acabam por especializar-se em determinadas temáticas, quanto aos objetos estudados. Entretanto, esta fragmentação de temas investigados ocorre de forma conjunta à significativa interdisciplinaridade $^{16}$ dentro das Ciências Agrárias, já que muitos dos temas pesquisados são investigados por mais de um programa e, em alguns casos particulares, as investigações são realizadas sob uma mesma abordagem teórico-metodológica. Além do mais, certos programas compartilham muitos de seus docentes orientadores, e isso faz com que as pesquisas nestas áreas apresentem grande justaposição. Isso é evidente entre os programas de Genética e Melhoramento de Plantas e o de Fitotecnia, que têm boa parte de seus orientadores atuando nos dois programas.
Entretanto, também fica perceptível que, os diferentes programas, em linhas gerais, têm particularidades quanto aos objetos de pesquisa. A sustentabilidade ambiental está presente, de alguma forma, nos discursos dos professores de todos os programas, em alguns programas este discurso está mais ativo, como são os casos da Engenharia Florestal, da Engenharia Agrícola e de Solos e Nutrição de Plantas. Coelho (1999) já havia lembrado que, a Engenharia Agrícola e a Engenharia Florestal, em suas gêneses, se constituíram como áreas de atuação profissional localizadas entre a busca por conservação ambiental e a grande produção agrícola voltada para o mercado.

Como vincular o universo dos temas pesquisados, apresentados no quadro acima, aos interesses e necessidades específicos de um dado setor ou grupo da sociedade? O que se percebe, no geral, é uma grande aproximação do conhecimento científico

${ }^{16}$ Embora a modernização da Ciência tenha levado à sua intensa "fragmentação", disciplinarizando o conhecimento, alguns teóricos vêem discutindo, sobretudo nas últimas décadas, a importância de pensamentos interdisciplinares, onde os fenômenos e experimentos são analisados e desenvolvidos a partir de diferentes saberes interdependentes (WEIL; D’AMBROSIO; CREMA, 1993). 
produzido com as diversas necessidades criadas socialmente, politicamente e economicamente. Isto é facilmente observado nas temáticas pesquisadas. Outra faceta da influência dos fatores sociais, políticos e econômicos na produção do conhecimento científico pode ser observada a partir dos principais motivos apontados pelos pesquisadores do CCA/ UFV como tendo levado os mesmos a desenvolver suas pesquisas.

Ao se referir aos fatores que concebem como os que influenciam na realização de suas investigações científicas, $38 \%$ dos pesquisadores mencionaram "a busca por reconhecimento no meio acadêmicoprofissional”. Esses dados corroboram c a idéia de Latour e Woolgar (1997), de que a procura pelo crédito e pela credibilidade são os maiores incentivadores para os pesquisadores realizarem suas pesquisas.

A "existência de editais públicos de pesquisa" foi a segunda causa mais lembrada como influência para a realização das investigações científicas desenvolvidas pelos pesquisadores, e ela foi citada por $35,2 \%$ dos entrevistados. Além de esses editais demonstrarem um campo de oportunidades aberto pelo Estado para a escolha das pesquisas a serem desenvolvidas pelos pesquisadores, neles também se observa a influência dos interesses estatais para a condução das pesquisas realizadas neste Centro de Pesquisa. Merece realce ponderar que, para obter aprovação em nesses editais, muitas avaliações são feitas aos projetos e aos pesquisadores e, salvaguardando as especificidades de cada edital ou órgão financiador, um dos atributos mais importantes para a aprovação é a produtividade do pesquisador dentro da sua área de conhecimento e da comunidade científica à qual está vinculado. A iniciativa privada, porém, também pode abrir um campo de investigação para os pesquisadores. Para obter investimentos da iniciativa privada ${ }^{17}$ para a realização de pesquisas, o pesquisador precisa, além, obviamente, de desenvolver pesquisas que interessam ao possível financiador, ter construído uma sólida carreira - comprovada por meio de seu currículo, dentre outras formas - e demonstrar a credibilidade e a conseguinte confiabilidade que possuem suas pesquisas.

Quadro 2 - Fatores mais lembrados pelos pesquisadores entrevistados* do CCA/UFV como influenciando na realização de suas pesquisas

\begin{tabular}{|c|c|c|c|c|c|c|c|c|c|c|c|c|}
\hline \multirow[t]{2}{*}{ Fatores (motivos) } & \multirow[b]{2}{*}{$\mathbf{a}$} & \multirow[b]{2}{*}{ b } & \multicolumn{10}{|c|}{ Programas de pós-graduação } \\
\hline & & & c & d & $\mathbf{e}$ & $\mathbf{f}$ & $\mathbf{g}$ & h & $\mathbf{i}$ & $\mathbf{j}$ & Total & $\%$ \\
\hline $\begin{array}{l}\text { Existência de editais públicos } \\
\text { de pesquisa }\end{array}$ & 3 & 0 & 2 & 1 & 3 & 7 & 2 & 2 & 3 & 1 & 24 & 35,2 \\
\hline $\begin{array}{l}\text { Oportunidades abertas pela } \\
\text { iniciativa privada }\end{array}$ & 2 & 0 & 1 & 1 & 1 & 5 & 2 & 0 & 2 & 0 & 14 & 20,5 \\
\hline $\begin{array}{l}\text { Busca por reconhecimento e } \\
\text { destaque no meio acadêmico- }\end{array}$ & 3 & 1 & 4 & 1 & 4 & 6 & 4 & 1 & 1 & 1 & 26 & 38,2 \\
\hline $\begin{array}{lll}\text { profissional } & & \\
\text { Aumento dos } & \text { ganhos } \\
\text { financeiros } & & \\
\end{array}$ & 1 & 0 & 0 & 1 & 2 & 4 & 1 & 1 & 1 & 1 & 12 & 17,6 \\
\hline $\begin{array}{l}\text { Possibilidade de solucionar } \\
\text { problemas práticos existentes }\end{array}$ & 1 & 3 & 2 & & 3 & 2 & 4 & & 3 & 2 & 20 & 29,4 \\
\hline
\end{tabular}

17 É importante se destacar que, o fato destas pesquisas serem demandadas pela iniciativa privada não significa que elas não sejam de interesse da sociedade em geral, visto que a iniciativa privada procura, também, ocupar espaços abertos pelas necessidades socialmente existentes. 
continuação...

\begin{tabular}{|l|llllllllllll|}
\hline $\begin{array}{l}\text { Determinação do programa } \\
\text { de pós-graduação que está } \\
\text { vinculado }\end{array}$ & 0 & 0 & 0 & 0 & 0 & 2 & 2 & 0 & 0 & 1 & 3 & 4,4 \\
\hline $\begin{array}{l}\text { Atender às demandas por } \\
\text { conhecimento pessoal, dos } \\
\text { orientandos ou de sua área de } \\
\text { pesquisa }\end{array}$ & 4 & 2 & 1 & 3 & 1 & 0 & 1 & 0 & 3 & 3 & 18 & 26,4 \\
\hline
\end{tabular}

Fonte: Dados de pesquisa, 2009.

* Professores orientadores dos programas de pós-graduação stricto sensu do Centro de Ciências Agrárias da Universidade Federal de Viçosa
a. Pós-graduação em Ciência florestal
b. Pós-graduação em Economia aplicada
c. Pós-graduação em Engenharia agrícola
d. Pós-graduação em Extensão rural
e. Pós-graduação em Fitopatologia
f. Pós-graduação em Fitotecnia
g. Pós-graduação em Genética e melhoramento
h. Pós-graduação em Metereologia agrícola
i. Pós-graduação em Solos e nutrição de plantas
j. Pós-graduação em Zootecnia

Ocurrículoaparece, então, comoomaisimportante instrumento para avaliar todo o investimento feito na carreira dos pesquisadores (LATOUR; WOOLGAR, 1997). E para que um docente aperfeiçoe o seu currículo, este deve ter um bom desempenho em sua carreira acadêmico-profissional, alcançando, consequentemente, reconhecimento e notoriedade entre seus pares. Da mesma forma, na medida em que seu currículo enriquece, o pesquisador ganha crédito e credibilidade, obtendo destaque e reconhecimento. Isto explica a preocupação dos pesquisadores em manterem os currículos atualizados ${ }^{18}$, expondo as atividades e as "conquistas" recentes, como: publicações, participações em congressos, em bancas de defesas de teses, de concursos, prêmios, dentre outras informações. Também merece destaque que há uma imposição por parte dos órgãos financiadores de pesquisa, de maneira geral, que os professores mantenham seus currículos digitais atualizados, tornando fundamental este procedimento para que os professores consigam financiamento de suas pesquisas.

Os pesquisadores que mantêm os seus currículos atualizados, como os do CCA/UFV, apresentam, publicamente, o saldo dos investimentos efetuados às suas carreiras, incluindo as aquisições recentes, expondo todo o crédito e credibilidade de suas pesquisas, aumentando a possibilidade de alcançarem mais sucesso em suas carreiras, com mais aprovações em editais e mais oportunidades com a iniciativa privada.

A preocupação dos professores com o prestígio indica a influência de fatores sociais, econômicos e políticos na condução de suas pesquisas, já que conquistando prestígio, os mesmos aumentam as chances: a) de serem bem reconhecidos entre seus pares - aumentando, inclusive, as chances de premiações -; b) de obterem financiamento de suas pesquisas pela iniciativa privada; c) e de conseguirem aprovação em editais públicos de pesquisa.

\footnotetext{
18 Todos os professores entrevistados tiveram seus currículos da Plataforma Lattes analisados e, a partir de tal análise, viu-se que todos estes pesquisadores apresentavam em seus currículos alguma informação sobre atividades realizadas no ano de 2009 , demonstrando o interesse dos mesmos em mantê-los atualizados.
} 
Quadro 3 - Contribuições mais lembradas pelos pesquisadores entrevistados* do CCA/UFV de suas pesquisas para a sociedade

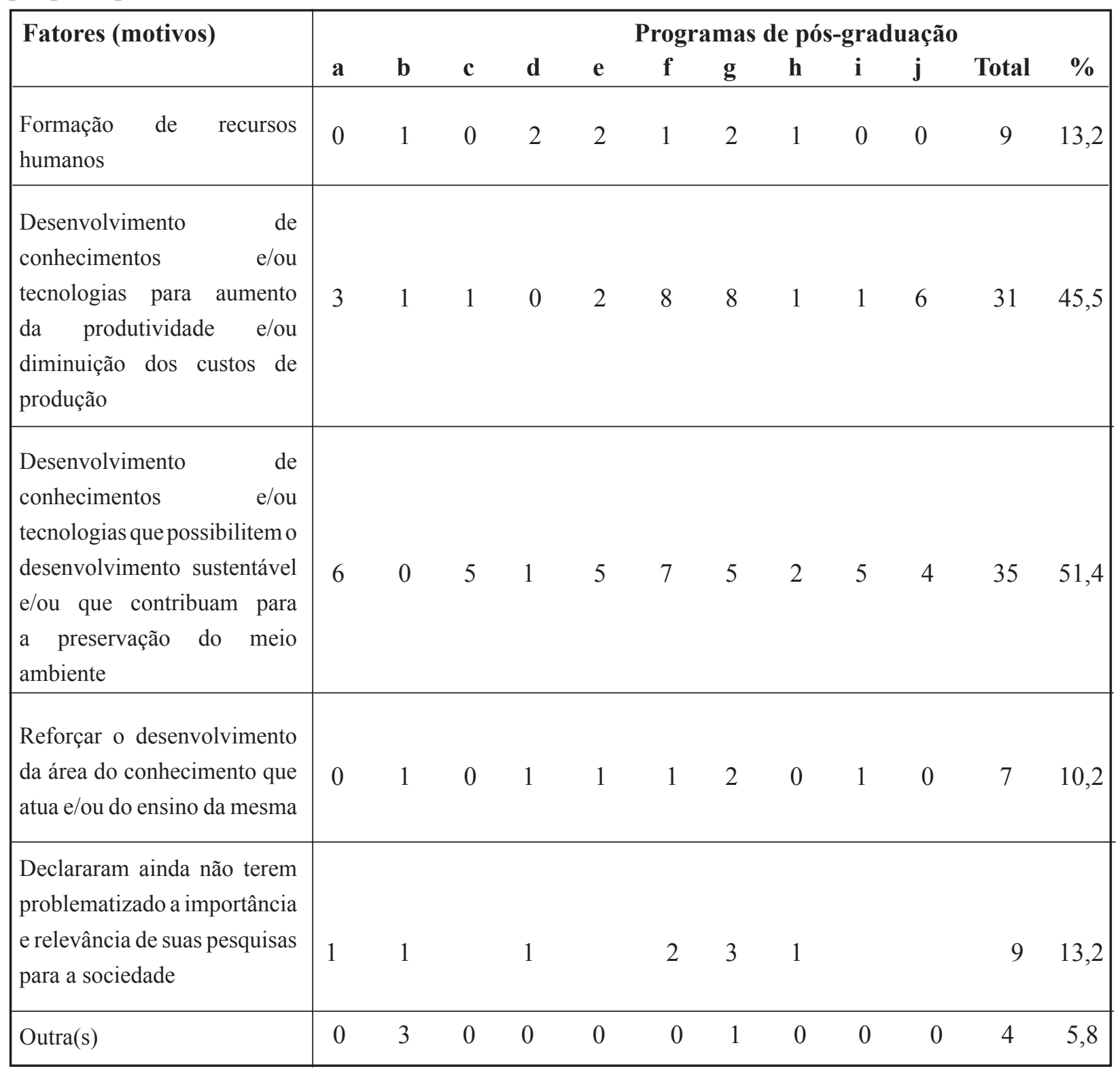

Fonte: Dados de pesquisa, 2009.

* Professores orientadores dos programas de pós-graduação stricto sensu do Centro de Ciências Agrárias da Universidade Federal de Viçosa
a. Pós-graduação em Ciência florestal
b. Pós-graduação em Economia aplicada
c. Pós-graduação em Engenharia agrícola
d. Pós-graduação em Extensão rural
e. Pós-graduação em Fitopatologia
f. Pós-graduação em Fitotecnia
g. Pós-graduação em Genética e melhoramento
h. Pós-graduação em Metereologia agrícola
i. Pós-graduação em Solos e nutrição de plantas
j. Pós-graduação em Zootecnia 
Outra forma de se visualizar como a influência das preocupações e demandas sociais se manifestam nas investigações científicas conduzidas pelos pesquisadores do CCA/UFV pode ser observada no quadro 3, que expõe as contribuições que os pesquisadores julgam estar dando em prol do "desenvolvimento de conhecimentos e/ou tecnologias para o aumento da produtividade e/ ou diminuição dos custos de produção"; e para o "desenvolvimento de conhecimentos e/ou tecnologias que possibilitem o desenvolvimento sustentável e/ou que contribuam para a preservação do meio ambiente".

Viu-se que 13,2\% dos pesquisadores entrevistados "declararam ainda não terem problematizado a importância e relevância de suas pesquisas para a sociedade". Certamente, isto não significa concluir que os professores do CCA/UFV, de uma maneira geral, não agem de forma reflexiva, entretanto, esta ocorrência, mesmo pouco representativa em relação ao universo pesquisado, está de acordo com o que enunciou Habermas (2007). Para o autor, a produção capitalista moderna incorporou consigo o formato em que é produzida e para quê é produzida a Ciência, fazendo com que a falta de reflexividade ${ }^{19}$ existente no processo produtivo também fosse transferida para os cientistas que geram as inovações, que agora dependem o setor produtivo.

No que diz respeito ao "desenvolvimento de conhecimentos elou tecnologias para aumentar a produtividade elou diminuir os custos de produção"; lembrada por $45,5 \%$ dos entrevistados, percebemos que o discurso dos professores está consonante com a preocupação da humanidade que existe desde os primórdios das civilizações sedentárias ${ }^{20}$ : aumentar a produtividade da terra e do trabalho. Como Graziano da Silva (2003,p.14) chama a atenção “[...] a existência do tempo de trabalho excedente pode ser considerada simultaneamente, como a condição e a mola mestra de todo o desenvolvimento social, econômico e cultural da humanidade”. Assim, no que diz respeito à produção do conhecimento científico gerado pelas práticas dos pesquisadores do CCA/UFV, segundo estes, vai de encontro ao que destaca o Graziano da Silva, quando afirma também que "[...] o progresso técnico na agricultura é essencial porque se relaciona diretamente com a redução do trabalho necessário para a reprodução social" (SILVA, 2003, p. 14).

Já no que diz respeito aos pesquisadores considerarem que as suas pesquisas contribuem para a "promoção de conhecimentos elou tecnologias que possibilitam o desenvolvimento sustentável $e$ a preservação do meio ambiente", lembrada por $51,4 \%$ dos professores, novamente percebemos a influência das preocupações socialmente vigentes na conduta e nos discursos dos cientistas. Desenvolver tecnologias limpas e sustentáveis, além de se constituírem em uma política de incentivo do Estado, passou a fazer parte constitutiva das preocupações do mundo contemporâneo, a partir das crises ambientais vividas no século XX (BRÜSEKE, 2001).

\section{Conclusão}

Como discutido neste artigo, a Ciência, por ser um produto social - e não um agente externo à sociedade -, é caracterizada como o resultado de uma complexa rede de interesses: sociais, econômicos, políticos e culturais. Neste sentido, como identificado nas respostas dos professores do CCA/UFV, fatores que vão "da vaidade do pesquisador" ao incentivo estatal e aos recursos ofertados pela iniciativa privada contribuem para a direção das práticas dos pesquisadores. Do mesmo

\footnotetext{
${ }^{19}$ Esta falta de reflexividade ocorre devido ao fato de muitos dos indivíduos que compõem o processo produtivo não problematizarem sobre quais os reais interesses que influenciam para o desenvolvimento de tal produção (HABERMAS, 2007).

${ }_{20}$ Povos que abandonaram o nomadismo, estabeleceram-se em locais fixos e, consequentemente, aumentaram suas preocupações em relação ao desenvolvimento agrícola.
} 
modo, se por um lado é verdade que na produção do conhecimento interferem os fatores econômicos, estes não estão completamente desconectados com as necessidades e desejos socialmente construídos. Os discursos dos professores expressam como, de maneira geral, os mesmos crêem na relevância de suas pesquisas para a sociedade, independente da fonte de financiamento das mesmas.

Desta forma, vê-se que os conhecimentos científicos produzidos pelos professores orientadores do CCA/UFV estão em consonância com as lógicas da Ciência moderna, em que, entre outras coisas, além de haver uma grande especialização dos cientistas, o setor produtivo exerce importante influência na produção científica. Por fim, merece destaque o fato dos discursos dos professores explicitarem a preocupação dos mesmos em demonstrarem que suas práticas estão de acordo com as demandas e necessidades da sociedade moderna, como o da busca pelo aumento da produção de alimentos e da busca pelo desenvolvimento sustentável.

\section{Referências}

ALBUQUERQUE, Eduardo da Motta e. Catching up no século XXI: construção combinada de sistemas de inovação e bem-estar social. In: SICSÚ, João; MIRANDA, Pedro (Org.). Crescimento econômico: estratégias e instituições. Rio de janeiro: IPEA, 2009. p. 55-84.

ALVES, Elizeu Roberto de Andrade; SZMRECSANYI, Tamas; MARCOS, Zilmar Ziller. Pesquisa básica versus pesquisa aplicada na agropecuária. In: MARQUES, Edmundo $\mathrm{K}$. (Coord.). Ciência e Tecnologia na Agropecuária. Porto Alegre: FAPERGS, 1982. p. 51-59.

ANDRADE, Thales de. Inovação tecnológica e questão ambiental: dando um passo acima. In: JACOBI, Pedro; FERREIRA, Lúcia da Costa (Org.). Diálogos em ambiente e sociedade no Brasil. São Paulo: Annablume, 2006. p. 171-191.

BACON, Francis. Nova Atlântida. São Paulo: Abril Cultural, 1984.

BENAKOUCHE, Tâmara. Tecnologia é sociedade: contra a noção de impacto tecnológico. Cadernos de Pesquisa, São Paulo, n. 17, p. 2-28, 1999.

BONDI, Herman. Que é progresso em ciência? In: HARRÉ, Ron (Org.). Problemas da revolução cientifica. Belo Horizonte: Italiana Limitada, 1976. p. 17-26.

BRÜSEKE, Franz Josef. A técnica e os riscos da modernidade. Florianópolis: UFSC, 2001.

COELHO, France Maria Contijo. A construção das profissões agrárias. 1999. Tese (Doutorado em Sociologia) - Universidade de Brasília, Brasília.

DAGNINO, Renato; BRANDÃO, Flávia Cruvinel; NOVAES, Henrique Tahan. Sobre o marco analítico conceitual da tecnologia social. In: LASSANCE, A. E. Tecnologia social: uma estratégia para o desenvolvimento. Rio de Janeiro: Fundação Banco do Brasil, 2004. p. 15-64.

DESCARTES, René. Discurso do método. São Paulo: Martins Claret, 2005.

FONTES, Alice; CARDOSO, Alessandra. Formação de professores de acordo com a abordagem Ciência/ Tecnologia/Sociedade. Revista Electrónica de Enseñanza de las Ciências, v. 5, n. 1, p. 15-30, 2006.

HABERMAS, Jurgen. Técnica e ciência como ideologia. Lisboa: Ed. 70, 2007.

HENRY, John. A revolução cientifica e as origens da ciência moderna. Rio de Janeiro: Jorge Zahar, 1998.

KUHN, Thomas S. A estrutura das revoluções cientificas. São Paulo: Perspectiva, 1987.

LATOUR, Bruno; WOOLGAR, Steve. A vida de laboratório: a produção dos fatos científicos. Rio de Janeiro: Relume Dumará, 1997.

MEIS, Leopoldo de. Os cientistas e as implicações socioeconômicas da distribuição da ciência e recursos humanos no planeta. In: MUSA, Edson Vaz et al. (Org.). Ciência e tecnologia: alicerces do desenvolvimento. São Paulo: COBRAM, 1994. p. $13-21$.

MORAES NETO, Benedito Rodrigues. Marx, Taylor, Ford: as forças produtivas em discussão. Brasília: Brasiliense, 1991. 
NEVES, José Pinheiro. Por uma alternativa ao construtivismo social e ao determinismo técnico: a perspectiva de Lebeau e Simondon. In: VEIGA, Carlos Veloso; RABOT, Jean-Martin (Coord.). Novas tecnologias, utopia e imaginário. Braga: Necsum, 2006a. p. 101-113.

NEVES, José Pinheiro. O apelo do objecto técnico. Porto: Campo das letras, 2006b.

PERMEBIDA, Adriano. Desenvolvimento rural e o campo tecnocientífico: a construção de um discurso. 2004. Dissertação (Mestrado em Desenvolvimento Rural) - Universidade Federal do Rio Grande do Sul, Porto Alegre.

ROUANET, Paulo Sérgio. As razões do iluminismo. São Paulo: Companhia das letras, 1989.

SCHWARTZMAN, Simon. A pesquisa científica e o interesse público. Revista brasileira de inovação, Rio de Janeiro, v. 1, n. 2, p. 361-395, 2002.

SILVA, José Graziano da. Tecnologias e agricultura familiar. Porto Alegre: UFRRGS, 2003.

TEIXEIRA, Olívio Alberto; LAGES, Vinícius Nobre. Do produtivismo à construção da agricultura sustentável: duas abordagens pertinentes à questão. Cadernos de Ciência e Tecnologia. Brasília, v. 13, n. 3, p. 347-368, 1996.

TRIOLA, Mário F. Introdução à estatística. 9. ed. Rio de Janeiro: LTC, 2005.

WEIL, Pierce; D'AMBROSIO, Ubiratan; CREMA, Roberto. Transdisciplinaridade sistemas abertos de conhecimento. São Paulo: Sumus, 1993. 
